\title{
Comunicación para vivir y no morir en África
}

\author{
Max Tello Charún
}

Recibido: 21/9/2010

Aceptado: 30/10/2010

$\mathrm{E}$

scribo este artículo desde Bangui, capital de la República Centroafricana, donde me encuentro en misión. Llegué al África el 2000, después de muchos años de dedicación a la comunicación para el desarrollo en América Latina. Los países de esta región donde había trabajado habían alcanzado un nivel de desarrollo que les permitía hacer, a través de las instituciones públicas, mucho de lo que antes hacían los proyectos de cooperación internacional. De hecho, ese es un cambio importante: cuando el país se apropia de su desarrollo y lo hace por sí mismo.

Llegué a Mozambique. Mi tema era hacer comunicaciones para la salud materna. Cuando se trabaja en la cooperación internacional uno tiene un primer reto: trabajar con los colegas del sector público local. Eso no es fácil. En el sector público suele haber dos grupos: los políticos y los técnicos. Los primeros suelen estar vinculados a los gobiernos y por lo general son los que toman decisiones; los segundos vienen haciendo el trabajo técnico por años sin mucho reconocimiento de sus esfuerzos. En países africanos de habla portuguesa eso es muy evidente. Mis experiencias en Mozambique y Angola me enseñaron que debía hacer funcionar ambos lados de manera armónica, sin preocuparme mucho de hacer juicios de valor ni de tomar partido. Yo no iba a cambiar eso, a mí lo que me interesaba era que se establecieran comunicaciones para mejorar la calidad de vida de las personas. Y esa creo que es la misión de un comunicador para el desarrollo: contribuir a mejorar la calidad de vida de las personas.

Sin embargo, no debemos esperar que el cambio sea un todo, holístico e inmenso. Lo realista es avanzar por cambios menores que se van sumando en un bien mayor. Planificación familiar es un cambio en la conducta y actitud de las personas que mejora la calidad de vida de las familias, empodera a las mujeres y les brinda oportunidades de desarrollo. Vacunar contra la polio es un cambio conductual que libera a la sociedad de tener miles de personas inválidas, con escasa capaci- 
dad de producción, constituyendo un costo enorme para sus familias, con vidas destruidas y miserables. La mayor parte de las personas con polio sufren mucho emocionalmente, imagínense su vida en familias de escasos recursos en países de carestía.

Que el político y el técnico funcionen de manera armónica consiste más o menos en lo siguiente. El político tiene el poder y toma decisiones que apoyan el cambio de conducta que deseamos. El técnico implementa el programa relativo a esas decisiones. El político pone recursos y saca dividendos políticos. El técnico pone el know how y el esfuerzo, y a cambio obtiene prestigio y proyecciones en su vida profesional. Ninguno hace nada si no obtiene algo. Ese algo puede ser más poder o más prestigio, que tarde o temprano se transforma en oportunidades económicas para su familia. Punto. Toda la retórica de ideales, valores, etcétera, es solo discurso para justificar una práctica. El interés es lo que mueve la economía de la sociedad, y por supuesto los proyectos de desarrollo no están excluidos.

Mi experiencia organizando campañas de vacunación ha sido un privilegio. Muy rápidamente pasé de la salud reproductiva a las vacunaciones. Había hecho mucha comunicación para salud reproductiva en América Latina, con programas del Johns Hopkins y del Fondo de las Naciones Unidas para Actividades en materia de Población (UNFPA, por sus siglas en inglés). África significó muchos programas de vacunación con la OMS y la Unicef. En Angola las campañas de vacunación eran fiestas nacionales, en Uganda eran movilizaciones políticas.

Johanna Márquez era una inmensa señora que controlaba toda la movilización social en Luanda, capital de Angola. Cientos de movilizadores sociales salían a las calles a promover las diferentes campañas de salud a la sola voz de doña Johanna. Mi amiga ya se fue a movilizar angelitos negros en el cielo... pero cuando la conocí aprendí mucho de la importancia de la comunicación interpersonal en las sociedades africanas. Las redes sociales son la base del impacto de una campaña. Los líderes locales, Sobas, que aún usaban un uniforme caqui como en tiempos coloniales, visitaban casa por casa convocando a la vacunación. Los jóvenes organizados en brigadas de movilizadores al estilo cubano armaban revuelo en todos los lugares públicos distribuyendo folletos y gritando a través de megáfonos. Los pastores cristianos, de iglesias brasileñas y nigerianas, han derrotado a los curas católicos, y se han convertido en un aliado de toda campaña de salud o de cambio social; en caso de no llegar a un acuerdo con ellos podrían despotricar contra nuestros propósitos y hacernos la vida imposible. Las mujeres, también organizadas al estilo cubano, son otro canal para promover cambios, dentro de un enfoque de género que avanza muy lentamente en el imaginario femenino de las mujeres afri- 
canas. Cuba ha tenido una influencia enorme en África. Hace treinta años apoyó los movimientos de independencia de muchos países, enviando tropas, médicos y maestros. Los ejércitos de Angola y Mozambique fueron directamente entrenados y liderados por oficiales cubanos que no dudaron en participar en sus guerras de independencia y en la defensa de sus territorios. Fue un ejército cubano el que defendió Angola y venció a las tropas racistas de Sudáfrica dirigidas por los Boers Afrikaans. Pero también fueron maestros y médicos cubanos quienes desarrollaron los sistemas educativos no solo de los países de habla portuguesa, sino que participaron en el desarrollo de países de habla inglesa y francesa. La humilde Cuba fue para África en el siglo XX lo que Francia fue para América Latina en el XIX y para Estados Unidos en el XVIII.

En Angola, como en Lima, el ruido está en todas partes. Es una sociedad bulliciosa y alegre, dispar en sus diferencias, con una miseria descontrolada e insondable. Cuando pensaba que ya había visto lo peor, siempre había un nivel más abajo. Angola es un país que hoy se jacta en CNN de ser petrolero y espacio para oportunidades de inversión. Esto es verdad, pero la riqueza no llega a la mayor parte de la población, que vive un sueño ajeno jactándose de ser la sociedad más cara del mundo... También es cierto, vivir en Luanda es más caro que en Ginebra o en Tokio, con un costo-beneficio mucho menor.
En los ochenta, cuando yo andaba por Europa soñando con trabajar en comunicación para el desarrollo, Jonathan Gaifuba dirigía en Uganda la primera campaña contra el sida en el mundo. No se trataba solo de una desconocida enfermedad, cuya transmisión no era completamente clara, cuyos síntomas eran desconocidos en toda su magnitud y su futura extensión era insospechada. Se trataba de una campaña que incluía un fuerte componente de desestigmatización. Los ugandeses estaban aterrorizados y en su pánico habían matado a más de un presunto portador de la enfermedad. Jonathan tenía un doble reto: enseñar a prevenir lo desconocido y a vivir con el peligro. Me tocó trabajar con Jonathan Gaifuba el 2003; organizamos la campaña de vacunación que terminó con el sarampión en Uganda. Esta fue una experiencia extraordinaria.

Cuando llegué a Uganda el 2003, había 50.000 casos de sarampión y 3.000 muertos al año por esta enfermedad. Realizamos una campaña mezcla de movilización social y comunicación masiva. Cuando nos conocimos Jonathan me demostró la velocidad de organización de las redes sociales. Me preguntó mostrándome el mapa: "¿Max, dónde quieres que sea la reunión comunitaria mañana?". Yo le señalé un punto a unos 200 kilómetros de Kampala, la capital del país. Al día siguiente, a las tres de la tarde, jestaban reunidas todas las autoridades y la comunidad con Jonathan y conmigo! El viejo comunicador me dio una 
lección de redes sociales y estaba muy orgulloso de la capacidad de organización del país. Uganda tiene una de las estructuras políticas más sólidas de África, basándose en la cultura militar el presidente Museweni ha organizado su país como un ejército en permanente alerta. Y esto no es metáfora, Uganda ha participado victoriosamente en muchos conflictos en la región. Por ejemplo, cuando Francia y Bélgica huían de la responsabilidad, Uganda fue el respaldo del actual presidente de Rwanda, Paul Kagame, en su lucha para terminar en su país con el genocidio de los Tutsies por los Hutus.

Una tarde, el representante de la OMS en Uganda, un experimentado doctor africano llamado Oladapo Walker, me llamó a su oficina. Estaba enojado con los materiales de la campaña producidos por una ONG americana. No quería poner su logotipo en "esos papeles color amarillo". Eran de verdad horribles. Me dijo: "Muéstrame fotos, quiero hacer algo con niños típicamente ugandeses, no estos niños ricos que parecen sacados de la escuela internacional". Nos pasamos viendo fotos de mi archivo, ya llevaba cuatro años por África y se detuvo en una niñita de un campo de refugiados, cargando a su hermanito a la espalda. Me dijo, “Max, estos son los niños que quiero, ponlos en los afiches, folletos y demás de la campaña. Hacemos todo de nuevo esta noche. Estos son niños típicamente ugandeses". No me quedó más remedio que darle al Photoshop y al Pagemaker toda la noche. Viejos amigos ambos. Hoy Pagemaker es un buen recuerdo, frente a mi nuevo engreído, el Adobe InDesign. El layout estaba listo al día siguiente; imprimimos todo el día y al final del día todo se fue a distribución. Ah, me olvidaba, los niños eran angolanos y ningún ugandés lo notó ni le importó, pero eso ahora no interesa y espero que Oladapo me perdone si algún día lee este artículo. Siempre me ha sorprendido lo fácil que decimos que somos diferentes, cuando los seres humanos somos más similares de lo que parecemos. En la India hay muchos indios que son como yo. Y en Japón he pasado por japonés. $Y$ hay 400 mil peruanos que podrían ser africanos y muchos de nuestros blancos y mestizos peruanos podrían ser mozambicanos portugueses, boers sudafricanos o "coloured", que es como se llama a los mulatos en Sudáfrica.

El año siguiente, el 2004, volví a Uganda y fui a tomar fotos de los niños con sarampión en el hospital. Me encontré con el cuarto vacío y las camas desarmadas arrumadas en una esquina. No hubo un caso más de sarampión, 3.000 niños se habían salvado; 50.000 personas se habían librado de esta enfermedad. Esa noche me tomé dos scotchs celebrando en soledad, en el bar del hotel, que fue muy frecuentado por el famoso viajero Henry Morton Stanley.

La soledad es tu compañera cuando vas por el mundo como consultor 
de proyectos de desarrollo. Aprendes a disfrutarla y a aprovecharla. Yo realicé una maestría online en Information Technology, por ejemplo. Pero la soledad tiene dimensiones antropológicas también, no es tu idioma, no es tu cultura. En África, solo se habla español en Guinea Ecuatorial, donde nunca he ido. En los otros países se habla portugués, inglés o francés. $\mathrm{Y}$ ese fue el orden de mi inducción. Había pasado de países de habla portuguesa a países de habla inglesa. Ya trabajaba en Sudáfrica, Zimbabwe, Zambia, Suazilandia, Botswana y otros. Había vuelto a los temas de salud sexual y reproductiva, adolescentes, género, sida. Andaba de país en país proveyendo asistencia técnica para proyectos del UNFPA, desde el diseño del proyecto, la investigación de audiencia, la implementación, el pretest, la producción de las piezas, la evaluación de impacto. Era un médico general que sacaba adelante al paciente de acuerdo con sus necesidades. Y tenía que hacerlo rápido, sin mucho protocolo ni palabrería. La retórica que tanto caracteriza nuestra cultura latina no existe en la cultura inglesa. El inglés es un idioma que va directo al grano, tiene sutilezas, pero no se pierde en construir expresiones ni vericuetos inútiles.

Desde el 2004 Zimbabwe fue mi base para moverme por todos los países del sur de África. El presidente Robert Mugabe, de 85 años, enfrentaba una oposición cansada de muchos años de un desgastado gobierno. Zimbabwe se debatía en una profunda crisis, acompañada de una hiperinflación diez veces mayor que la del primer gobierno de Alan García. El dinero valía nada. Pero los zimbabwenses eran las personas más tolerantes, cívicas y amables que he conocido. Donde hubieran podido devenir revoluciones, los zimbabwenses respondían con cordura y tolerancia. Son gente que ama a su país, que sabe que han sido los más ricos de África durante los tiempos coloniales, que tienen recursos naturales, técnicos y humanos para volver a su lugar, y que no quieren destruir su país en una lucha fratricida y desgastante. Ya pasaron por eso y prefieren hablar civilizadamente. El país es hermoso, a la altura de sus ciudadanos; desde el aire se observa el paso de Sudáfrica a Zimbabwe porque el paisaje se hace verde y lleno de agua. En medio de su crisis económica Zimbabwe se dio maña para reducir el flagelo del sida con sendos programas de comunicación y la participación entusiasta de jóvenes y mujeres que sabían que probablemente la economía no podía cambiar mucho, pero que ellos podían cambiar sus conductas y formas de relacionarse. Había que comunicarse de una manera diferente para poder vivir.

La misión del UNFPA en Zambia quería un video que mostrara sus proyectos a nivel nacional. Pasé un mes recorriendo Zambia, grabando imágenes para el video. Lo mismo hice en Malawi. El video es una forma de 
mostrar los avances de los proyectos. Es un excelente medio de fundraising $\mathrm{y}$ advocacy. El UNFPA lo tenía muy claro, imágenes que mostraran avances en sus intervenciones. Era 2006, todas las misiones soñaban con exponer sus progresos en video y un medio de creciente demanda, la World Wide Web. Así, dos programas más se sumaron a mi computadora, Pinnacle Studio para el video y Adobe Dreamweaver para hacer websites. Pinnacle Studio es un "programita" para la producción de video mucho más amigable que Adobe Premiere. Yo uso Premiere cuando necesito desarrollar algo con layers, integrado con Flash y un mayor nivel tecnológico. Studio es de mayor utilidad para productos más simples.

Videos y websites me hicieron recorrer palmo a palmo varios países. Hay algunos que conozco tanto o más que el Perú: Angola, Uganda, Zimbabwe, Malawi, Sambia, Sudáfrica, Lesotho.

Hoy Sudáfrica es el país más desarrollado de África. Sus ciudades son metrópolis al estilo occidental. Johannesburg es un Nueva York, Cape Town y Pretoria son muy modernas y hermosas. Recorrí Sudáfrica dos veces; la primera para diseñar un proyecto de educación sexual en las universidades sudafricanas, la segunda vez para producir el Plan de Acción Nacional Común de las agencias de Naciones Unidas en el país. Sudáfrica es el motor económico del continente. Es un costosísimo experimento de convivencia que trata de recuperar lo positivo del arco iris de razas de sus orígenes siguiendo la voz inspiradora de Nelson Mandela.

En los últimos años he tenido más misiones en países de habla francesa. Visité Rwanda dos veces para desarrollar una estrategia de comunicaciones para género. Rwanda, el país del genocidio, donde murieron 900 mil Tutsies en manos de sus compatriotas Hutus, se ha convertido en un país altamente monitoreado por los organismos internacionales. Nadie quiere otra catástrofe igual. Los genocidios son producto de las ambiciones de poder y económicas de individuos. Nunca existieron dos tribus, fueron los colonizadores belgas quienes clasificaron a los locales en dos grupos con fines de usar la separación para tener mayor control sobre ellos. Ambos grupos hablan el mismo idioma y tienen la misma cultura. Hoy quedan las heridas; sin embargo, Rwanda tiene el mayor porcentaje de mujeres en posiciones de poder en el mundo, tanto en los poderes Legislativo y Ejecutivo como en el local. Las mujeres, víctimas principales de la violencia, están sacando al país adelante. Ya nadie se atreve a hablar de tribus, todos somos rwandeses, dicen, en su intento de borrar un pasado muy cercano para ser recordado.

Cada año hay 200 mil casos y 30 mil muertos por fiebre amarilla. La mayor parte de ellos en África y América Latina. He dedicado el 2009 y el 2010 a prestar asistencia técnica a campañas de comunicación para va- 
cunaciones nacionales contra la fiebre amarilla. Ha sido una experiencia privilegiada derrotar ese flagelo en Sierra Leona, Guinea Conakry y República Centroafricana. Países enteros y millones de personas fueron vacunados pues escucharon el llamado de los medios de comunicación y las redes sociales. No importa qué idioma occidental estés hablando en África; tus comunicaciones siempre tendrán que ser traducidas a las lenguas nacionales, y estas pueden ser una o varias. Por eso debes tener una buena y clara relación con los comunicadores del país, tus colegas en las agencias de cooperación o en el Ministerio de Salud. Ellos son el puente para llegar a la población con tus estrategias y tener éxito. Brindar asistencia técnica no significa una relación vertical, pues cada día uno aprende de los colegas nacionales; significa un intercambio, una sinergia de conocimiento y experiencia. En comunicación para el desarrollo no hay autores; es un asunto de redes, de unir fuerzas entre el Estado, las agencias de cooperación y el sector privado; es partnership.

Ha sido un largo viaje protegido por la mano de Dios, rico en experiencias, descubriendo culturas, riquezas y bajezas de la humanidad. Un viaje en el que dediqué mi ciencia y mi arte a algo que iba más allá de mis expectativas: ayudar a vivir y no morir... y todo hace suponer que este viaje aún no termina. 